DOI: 10.15690/pf.v14i4.1761

А.М. Чомахидзе $\mathbf{1}^{\mathbf{1}}$, Е.И. Алексеева $\mathbf{1}^{\mathbf{2}}$, Р.В. Денисова
1 Национальный медицинский исследовательский центр здоровья детей, Москва, Российская Федерация
2 Первый Московский государственный медицинский университет им. И.М. Сеченова, Москва,
Российская Федерация

Опыт успешного применения адалимумаба у пациента с ювенильным артритом, ассоциированным с энтезитом и увеитом

Контактная информация:

Алексеева Екатерина Иосифовна, доктор медицинских наук, профессор, заведующая ревматологическим отделением НМИЦ здоровья детей Минздрава России, декан педиатрического факультета Первого МГМУ им. И.М. Сеченова

Адрес: 119991, Москва, Ломоносовский проспект, д. 2, стр. 1, тел.: +7 (499) 134-02-97, e-mail: alekatya@yandex.ru Статья поступила: 01.08.2017 г., принята к печати: 28.08.2017 г.

В статье описан случай успешного применения человеческих моноклональных антител к фактору некроза опухоли а адалимумабу у пациента с тяжелым течением ювенильного артрита, ассоциированного с энтезитом и увеитом, резистентного к нестероидным противовоспалительным препаратам, метотрексату, глюкокортикостероидам, которые применялись местно и ретробульбарно. Уже после первого введения адалимумаба купировался болевой синдром, значительно уменьшилась длительность утренней скованности, к 4-й нед лечения нормализовались лабораторные показатели активности болезни, купировалась активность увеита, к 12-й нед регрессировали воспалительные изменения в суставах и была констатирована фаза неактивной болезни. Длительность ремиссии суставного синдрома и увеита на фоне применения адалимумаба составила 26 мес. Нежелательных реакций на фоне проводимой терапии не зарегистрировано.

Ключевые слова: дети, ювенильный идиопатический артрит; артрит, ассоциированный с энтезитом; увеит, адалимумаб.

(Для цитирования: Чомахидзе А.М., Алексеева Е.И., Денисова Р.В. Опыт успешного применения адалимумаба у пациента с ювенильным артритом, ассоциированным с энтезитом и увеитом. Педиатрическая фармакология. 2017; 14 (4): 294-299. doi: 10.15690/pf.v14i4.1761)

\section{ВВЕДЕНИЕ}

Ювенильный идиопатический артрит (ЮИА) - системное иммуноагрессивное хроническое заболевание у детей в возрасте до 16 лет, характеризующееся развитием прогрессирующего артрита периферических суставов [1-3]. Одним из вариантов ЮИА, согласно классификации Всемирной лиги ревматологических ассоциаций (International League of Associations for Rheumatology, ILAR) (Эдмонтон, 2001, 2-й пересмотр), является артрит, ассоциированный с энтезитом, или SEA-синдром (Seronegativity Entesopathy and Arthropathy Syndrome). Согласно классификации Европейской лиги ревматологов (European League Against Rheumatism, EULAR), он удовлетворяет критериям юношеского

Aleksandra M. Chomakhidze ${ }^{1}$, Ekaterina I. Alexeeva ${ }^{1,2}$, Rina V. Denisova ${ }^{1}$

${ }^{1}$ National Medical Research Center of Children's Health, Moscow, Russian Federation

2 I.M. Sechenov First Moscow State Medical University, Moscow, Russian Federation

\title{
The Experience of Successful Use of Adalimumab in a Patient With Juvenile Arthritis Associated With Enthesitis and Uveitis
}

The article describes the case of successful use of human monoclonal antibodies to the tumor necrosis factor- $\alpha$ adalimumab in a patient with a severe course of juvenile arthritis associated with enthesitis and uveitis resistant to non-steroidal anti-inflammatory drugs, methotrexate, glucocorticosteroids that have been applied topically and retrobulbarly. After the first adalimumab administration, the pain syndrome was stopped, the duration of morning stiffness was significantly reduced, the laboratory indices of the disease activity were normalized by the 4 th week of treatment, uveitis activity was stopped, the inflammatory changes in the joints regressed and the phase of inactive disease was ascertained by the 12th week. The duration of remission of articular syndrome and uveitis during treatment with adalimumab was 26 months. Adverse reactions were not registered during therapy. Key words: children, juvenile idiopathic arthritis; arthritis associated with enthesitis; uveitis, adalimumab.

(For citation: Chomakhidze Aleksandra M., Alexeeva Ekaterina I., Denisova Rina V. The Experience of Successful Use of Adalimumab in a Patient With Juvenile Arthritis Associated With Enthesitis and Uveitis. Pediatricheskaya farmakologiya - Pediatric pharmacology. 2017; 14 (4): 294-299. doi: 10.15690/pf.v14i4.1761) 
анкилозирующего спондилоартрита. Для этого варианта болезни характерны наличие хронического воспалительного артрита с поражением суставов осевого и периферического скелета, сочетающегося с развитием энтезита; серонегативность по ревматоидному и антинуклеарному фактору; высокая ассоциация с носительством HLA-B27 и семейная агрегация болезни.

Энтезит - воспаление в местах прикрепления связок, фасций и сухожилий к костям. Наиболее часто энтезит развивается в области надколенника, бугристости большеберцовой кости, в месте прикрепления подошвенного апоневроза и ахиллова сухожилия к бугру пяточной кости.

Одним из внесуставных проявлений ЮИА является увеит - воспаление сосудистой оболочки глаза, что можно объяснить эмбриональным родством тканей суставов и сосудистой оболочки глаз, формирующихся из мезодермы. Течение увеита может быть острым, подострым и хроническим. При остром иридоциклите развивается инъекция конъюнктивы и склер, слезотечение, светобоязнь, боль в глазном яблоке. Процесс протекает с поражением радужной оболочки, реснитчатого тела, в отдельных случаях формируется панувеит. Для артрита, ассоциированного с энтезитом, характерно острое и подострое течение процесса. При прогрессировании воспаления развиваются дистрофия роговицы, катаракта (помутнение хрусталика); образуются спайки, приводящие к деформации зрачка и снижению реакции на свет. Поражение глаз сопровождается снижением остроты зрения вплоть до развития слепоты. Развитие и прогрессирование артрита и увеита приводят к значительному снижению качества жизни и быстрой тяжелой инвалидизации пациентов [3-5].

Лечение ЮИА представляет собой сложную задачу. В терапии этого заболевания используется широкий спектр препаратов - нестероидные противовоспалительные препараты (НПВП), глюкокортикостероиды, иммунодепрессанты из группы антиметаболитов, селективные иммунодепрессанты. Применение базисных противоревматических препаратов не позволяет добиться контроля над активностью болезни у многих пациентов. Метотрексат - «золотой стандарт" при лечении ЮИА помогает достичь ремиссии артрита и увеита не более чем у 40-70\% больных [6, 7].

Патогенез ЮИА характеризуется продукцией различных цитокинов. Основная роль в развитии воспаления при ЮИА отводится фактору некроза опухоли (tumor necrosis factor, TNF) $\alpha$, который обладает цитотоксическими, иммуномодулирующими, провоспалительными свойствами, приводит к развитию хронического воспаления в суставах, деструкции хряща и кости, поражению сосудистой оболочки глаз [8, 9]. С момента выяснения разрушительной роли TNF $\alpha$ было синтезировано 5 препаратов, блокирующих активность этого цитокина, - инфликсимаб (химерные человеческо-мышиные моноклональные антитела к TNF $\alpha$ ), адалимумаб (человеческие моноклональные антитела к TNF $\alpha$ ), голимумаб, цертолизумаба пэгол и этанерцепт (растворимый рецептор к TNF $\alpha$ ). В настоящее время в педиатрической ревматологии разрешены к применению только этанерцепт и адалимумаб. Соответственно, препаратом выбора при развитии артрита, ассоциированного с энтезитом и увеитом, и неэффективности стандартной противоревматической терапии у детей старше 4 лет является адалимумаб [10-14].

Иллюстрацией к вышеизложенному является представленный нами клинический случай.

\section{КЛИНИЧЕСКИЙ ПРИМЕР}

Пациент Данила Б., наблюдается в ревматологическом отделении Национального медицинского исследовательского центра здоровья детей (НМИЦ здоровья детей) с июля 2012 г. с диагнозом «Юношеский анкилозирующий спондилоартрит, ассоциированный с носительством HLA-B27. Увеит левого глаза, дистрофия роговицы, частичная осложненная катаракта".

Из анамнеза жизни известно, что ребенок родился от первой физиологически протекавшей беременности, срочных самостоятельных родов. Вес при рождении составил 3600 г, длина - 51 см. Оценка по шкале APGAR 7/8 баллов. Раннее психомоторное и физическое развитие соответствовало возрасту. Аллергических реакций не отмечалось. Ребенок привит соответственно возрасту до начала настоящего заболевания (до 8 лет). Наследственность: отец мальчика страдает болезнью Бехтерева.

Мальчик болен с сентября 2011 года (заболел в возрасте 8 лет), когда без видимых провоцирующих факторов появились гиперемия кожи, отечность в области 4-го пальца правой стопы. Ребенок был госпитализирован в хирургический стационар по месту жительства, где было исключено травматическое повреждение суставов. Получал антибактериальные препараты (цефотаксим) и НПВП (ибупрофен). Болевой синдром уменьшился, сохранялась припухлость в области 4-го пальца стопы. В ноябре 2011 г. появились боль при движениях, припухлость правого коленного сустава, при этом припухлость в области 4-го пальца правой стопы сохранялась, в связи с чем ребенок был госпитализирован в ревматологический стационар по месту жительства. При поступлении в стационар у ребенка был выявлен суставной синдром с поражением правого коленного сустава, межфаланговых суставов 4-го пальца правой стопы; длительность утренней скованности составила 1 ч. При обследовании в клиническом анализе крови зарегистрировано повышение скорости оседания эритроцитов (СОЭ) до 30 мм/4 (норма 0-10), в иммунологическом анализе - повышение сывороточной концентрации С-реактивного белка (СРБ) до 11 мг/л (норма до 5). Учитывая данные анамнеза, особенности клинической картины и результаты лабораторного обследования уставлен диагноз: "Ювенильный ревматоидный артрит, полиартрит, серонегативный вариант. Активность 2-й степени". В стационаре мальчик получал антибактериальные препараты и НПВП (ибупрофен). Учитывая неэффективность противовоспалительной терапии ребенку был назначен метотрексат для подкожного введения в дозе 10 мг/м² поверхности тела в неделю (9 мг/нед). На фоне проводимого лечения в состоянии мальчика наблюдалась положительная динамика: уменьшилась выраженность болевого 
синдрома, воспалительных изменений в пораженных суставах.

В январе 2012 года - вновь обострение суставного синдрома с поражением правого коленного, правого голеностопного, межфаланговых суставов I и IV пальцев правой стопы. Ребенок госпитализирован в ревматологический стационар по месту жительства. В стационаре в связи с прогрессированием суставного синдрома доза метотрексата повышена до 15 мг/м² поверхности тела в неделю, продолжена терапия НПВП. Мальчик был направлен в ревматологическое отделение Научного центра здоровья детей Минздрава России (в настоящее время Национальный медицинский исследовательский центр здоровья детей, НМИЦ здоровья детей) для коррекции терапии.

Впервые в ревматологическое отделение НМИЦ здоровья детей ребенок поступил в июле 2012 года - через 10 мес от начала заболевания. При поступлении состояние ребенка расценено как средней тяжести за счет развития полиартикулярного суставного синдрома. При физикальном обследовании выявлен асимметричный полиартрит с преимущественным поражением суставов нижних конечностей: экссудативные изменения; боль и ограничение движений в левом локтевом, правом коленном, правом голеностопном, межфаланговых суставах I, II и IV пальцев правой стопы, плюснефаланговых суставах правой стопы; припухлость в области правого грудино-ключичного сочленения. Отмечались энтезопатии в области надколенников, в месте прикрепления ахиллова сухожилия к бугристости пяточных костей, верхнего переднего гребня подвздошных костей, а также выраженное нарушение походки. Длительность утренней скованности составила 120 мин. В клиническом анализе крови: гемоглобин 115 г/л; число лейкоцитов 8,55×10\% /л (норма 5,8-13,6), тромбоцитов - 421 $\times 10^{9} /$ л (норма 150-580); повышение СОЭ до 27 мм/ч (норма 2-10). В иммунологическом анализе крови: сывороточная концентрация СРБ 15 мг/л (норма до 5), антинуклеарный фактор <1,0 ед/л (норма до 1,5). При проведении иммуногенетического анализа выявлено носительство В27 антигена I класса главного комплекса гистосовместимости. При проведении рентгенологического обследования коленных суставов выявлены околосуставной остеопороз и признаки формирования эрозии суставной поверхности в задненижнем отделе эпифиза бедренной кости, что свидетельствовало о прогрессировании костно-хрящевой деструкции. По данным магнитно-резонансной томографии илеосакральных сочленений достоверных признаков сакроилеита не выявлено. Мальчик осмотрен офтальмологом: при биомикроскопии глаз признаков увеита не выявлено.

Учитывая длительность терапии НПВП, ребенку была проведена эзофагогастродуоденоскопия: выявлены признаки обострения гастродуоденита, не ассоциированного с носительством Helicobacter pylori. Принимая во внимание данные анамнеза, особенности клинической картины, результаты лабораторно-инструментального обследования, ребенку был подтвержден диагноз «Юношеский анкилозирующий спондилоартрит, ассоциированный с носительством HLA-B27. Активность 2-й сте- пени. Рентгенологическая стадия 2. Функциональный класс 2".

В связи с быстрым прогрессированием суставного синдрома, развитием выраженной инвалидизации пациента, а также наличием признаков костно-хрящевой деструкции по данным рентгенологического обследования, учитывая неэффективность проводимой ранее иммуносупрессивной терапии, мальчик нуждался в назначении генно-инженерной биологической терапии, а именно блокаторов TNF $\alpha$. В этот период в Российской Федерации были зарегистрированы 2 ингибитора TNF $\alpha$ по показаниям “Ювенильный идиопатический артрит" адалимумаб с возраста 4 лет и этанерцепт с возраста 2 лет. В этот же период в ревматологическом отделении проводилось клиническое исследование эффективности и безопасности голимумаба (моноклональные антитела к TNF $\alpha$; препарат зарегистрирован в РФ в 2012 г. и разрешен к применению у пациентов старше 18 лет) у детей с юношеским полиартритом. Родителям ребенка и пациенту было предложено участие в клиническом исследовании. Было подписано информированное согласие, сданы необходимые анализы. Результаты анализов соответствовали критериям включения. Терапия голимумабом в дозе 30 мг/м² поверхности тела (29 мг/введение) по схеме 1 раз в 4 нед была инициирована 18.07.2012; также продолжена терапия метотрексатом. На фоне терапии голимумабом развилась ремиссия суставного синдрома, нормализовались лабораторные показатели активности болезни, зарегистрирована лекарственная ремиссия болезни. В марте 2014 г. голимумаб был отменен в связи с окончанием исследования. У ребенка отсутствовали признаки активности болезни. Была продолжена терапия метотрексатом для подкожного введения в дозе 15 мг/м² поверхности тела.

Через 4 мес, в июле 2014 г., у ребенка появились жалобы на покраснение левого глаза, светобоязнь, слезотечение и снижение остроты зрения. Мальчик был консультирован окулистом. Диагностирован острый иридоциклит левого глаза. Ребенок госпитализирован в офтальмологический стационар. Проводилась местная терапия увеита с использованием глюкокортикостероидов; учитывая выраженность воспалительных изменений, неоднократно проводились ретробульбарные инъекции глюкокортикостероидов. Несмотря на проводимую терапию, воспалительные изменения в левом глазу сохранялись. В конце сентября появились выраженная припухлость, покраснение I пальца правой стопы, сопровождаемые значительным болевым синдромом, повышением местной температуры. Учитывая особенности клинической картины, мальчик был госпитализирован в хирургический стационар с подозрением на острый остеомиелит. Ребенку проводились рентгенологическое обследование, пункционная биопсия проксимальной фаланги I пальца правой стопы. Диагноз остеомиелита был исключен. В этот же период отмечалось развитие обострения суставного синдрома.

В ноябре 2014 г. мальчик был повторно госпитализирован в ревматологическое отделение НМИЦ здоровья детей. При поступлении состояние оценивалось как тяжелое за счет выраженной инвалидизации, болево- 
го синдрома, активного увеита (рис. 1). При осмотре отмечались болевой синдром; воспалительные изменения в правом коленном (рис. 2), правом голеностопном, межфаланговых суставах I, II и IV пальцев правой стопы; энтезопатии в области передних верхних остей подвздошных костей, пяточных костей, надколенников. Длительность утренней скованности составляла более 3 ч. Ребенок был осмотрен офтальмологом, констатировано течение активного увеита левого глаза с развитием осложнений - дистрофии роговицы, частичной осложненной катаракты и вторичной компенсированной глаукомы. При обследовании в клиническом анализе крови отмечалось ускорение СОЭ до 35 мм/ч, повышение сывороточной концентрации СРБ до 30 мг/л (норма до 5); уровни ревматоидного и антинуклеарного факторов оставались в пределах нормы (табл.).

Учитывая обострение артрита, развитие острого иридоциклита, неэффективность терапии метотрексатом, глюкокортикостероидами (местно и в виде ретробульбарных инъекций), прогрессирование костно-хрящевой деструкции и воспалительных изменений в левом глазу с высоким риском развития слепоты, по жизненным показаниям ребенку была назначена терапия человеческими моноклональными антителами к TNF $\alpha$ адалимумабом. Перед назначением блокатора TNF $\alpha$ ребенку были выполнены компьютерная томография органов грудной клетки, квантифероновый тест. Туберкулиновые тесты (реакция Манту и Диаскинтест) не проводились в связи с течением активного увеита. По данным результатов обследования туберкулезный процесс исключен.

Адалимумаб вводили подкожно в дозе $24 \mathrm{мг} / \mathrm{M}^{2}$ поверхности тела 1 раз в 2 нед. Аллергических реакций на введение препарата зарегистрировано не было. Мальчик продолжал получать метотрексат в дозе

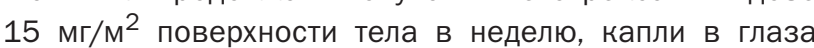
(метилпреднизолон, НПВП). Уже через 1 нед от начала терапии адалимумабом отмечена положительная динамика в виде уменьшения болевого синдрома в суставах и длительности утренней скованности. Через 2 нед
Рис. 1. Пациент Данила Б., возраст 11 лет: острый увеит левого глаза перед назначением адалимумаба

Fig. 1. Patient Danila B., age 11: acute left eye uveitis is diagnosed before adalimumab administration

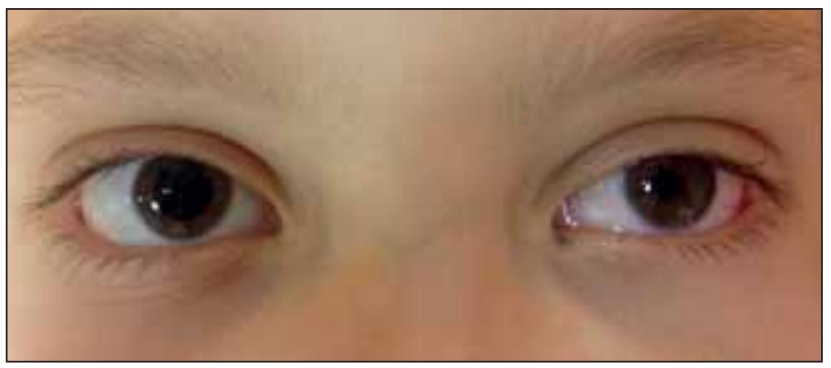

Примечание. Отмечаются инъекция сосудов слер, слезотечение, помутнение зрачка, сужение и неровность контура зрачка. Note. Injections of blood vessels, lacrimation, clouding of the pupil, narrowing and irregularity of the pupil are registered.

Рис. 2. Пациент Данила Б., возраст 11 лет: воспалительные изменения в правом коленном суставе перед назначением адалимумаба

Fig. 2. Patient Danila B., age 11: inflammatory changes in the right knee joint before adalimumab administration

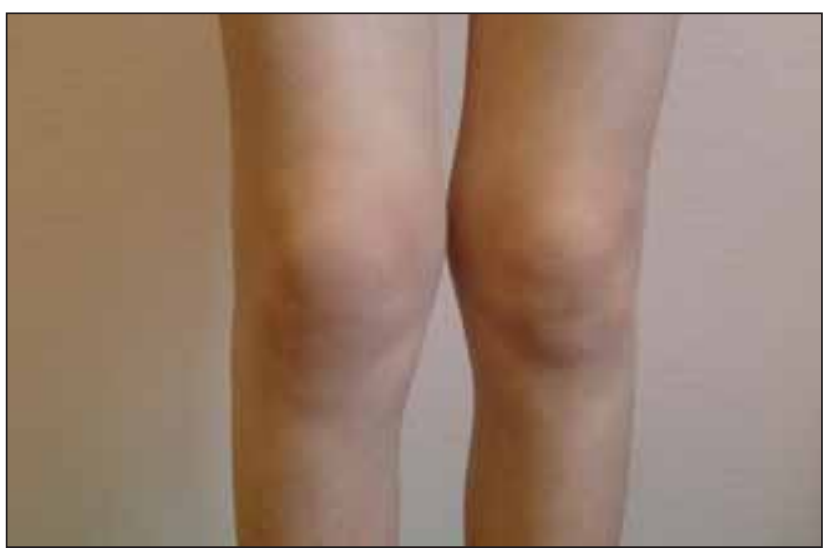

Примечание. Отмечаются припухлость коленного сустава, формирование сгибательной контрактуры.

Note. Swelling of the knee joint, formation of flexural contracture are registered.

Таблица. Динамика клинических и лабораторных показателей активности болезни у пациента Данилы Б., возраст 11 лет, на фоне терапии адалимумабом

Table. Clinical and laboratory indicators' dynamics of disease activity in the patient Danila B., age 11, in the setting of therapy with adalimumab

\begin{tabular}{|l|c|c|c|c|c|c|}
\hline \multirow{2}{*}{\multicolumn{1}{c|}{ Показатель }} & \multirow{2}{*}{$\begin{array}{c}\text { До } \\
\text { введения }\end{array}$} & \multicolumn{5}{c|}{ На фоне введения } \\
\cline { 3 - 7 } & $\mathbf{2}$ нед & $\mathbf{4}$ нед & $\mathbf{2 4}$ нед & $\mathbf{4 8}$ нед & $\mathbf{2}$ года \\
\hline Длительность утренней скованности, мин & 180 & 30 & 0 & 0 & 0 & 0 \\
\hline Число суставов с нарушением функции & 11 & 6 & 2 & 0 & 0 & 0 \\
\hline Число суставов с активным артритом & 11 & 6 & 0 & 0 & 0 & 0 \\
\hline СОЭ, мм/ч & 35 & 23 & 10 & 5 & 4 & 7 \\
\hline СРБ & 30 & 12 & $<0,5$ & $<0,5$ & $<0,5$ & $<0,5$ \\
\hline Улучшение по критериям АКР педи $\%$ & - & 50 & 75 & 100 & 100 & 100 \\
\hline Увеит & Активный & Активный & Вялотекущий & Ремиссия & Ремиссия & Ремиссия \\
\hline
\end{tabular}

Примечание. СОЭ - скорость оседания эритроцитов, СРБ - С-реактивный белок, АКР педи - педиатрические критерии Американской коллегии ревматологов.

Note. ESR - erythrocyte sedimentation rate, CRP - C-reactive protein, ACR $_{\text {pedi }}$ - pediatric criteria of the American College of Rheumatology. 
Рис. 3, А, Б. Пациент Данила Б., возраст 11 лет: положительные изменения внешнего вида на фоне терапии адалимумабом

Fig. 3, А, Б. Changes in the patient's appearance in the setting of therapy with adalimumab: A (eyes), B (knee joints)

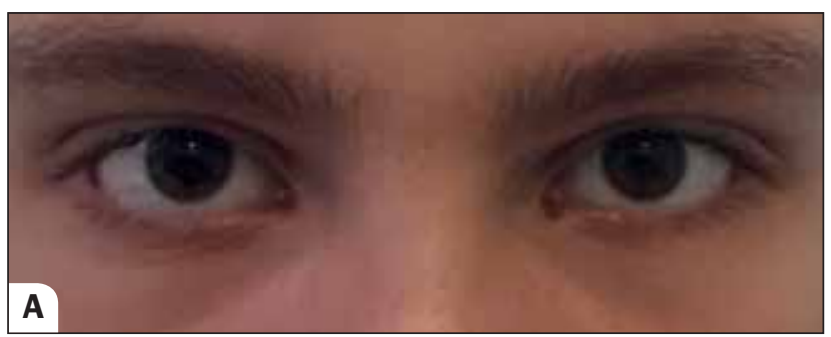

298

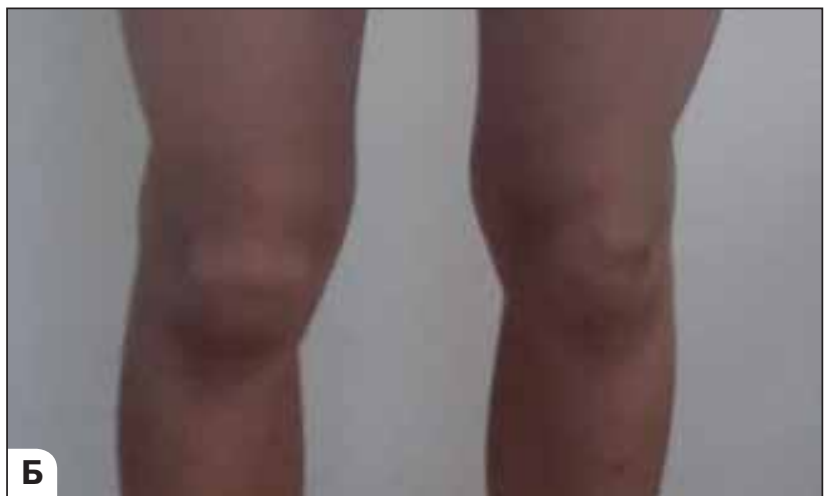

значительно уменьшились воспалительные изменения в суставах (см. табл.). После второй инъекции адалимумаба ребенок был выписан домой для продолжения терапии по месту жительства под контролем педиатра, ревматолога, офтальмолога.

В мае 2015 г. мальчик был госпитализирован в нашу клинику повторно для оценки эффективности и безопасности проводимой терапии. По данным медицинских документов, предоставленных пациентом, уже через 1 мес от начала терапии болевой синдром, скованность и воспалительные изменения в суставах купировались. Через 2 мес зафиксирована ремиссия увеита, поэтому частота инстилляций глазных капель была уменьшена до 1 капли 1 раз/сут. Через 6 мес у мальчика зарегистрирована стадия неактивной болезни (см. табл.): отсутствовали суставы с активным артритом, сохранялась ремиссия увеита, оставались нормальными лабораторные показатели активности болезни. Терапия адалимумабом и метотрексатом была продолжена. С момента начала терапии адалимумабом нежелательных явлений не зарегистрировано. Пациент продолжает лечиться адалимумабом и метотрексатом. Ремиссия болезни сохраняется в течение 2 лет (рис. 3).

\section{ОБСУЖДЕНИЕ}

Представленное клиническое наблюдение иллюстрирует течение артрита, ассоциированного с энтезитом. Клиническая картина заболевания соответствовала критериям диагностики: развитие асимметричного артрита с преимущественным поражением суставов ног, наличие энтезопатий, ассоциация с носительством HLA-B27, дебют заболевания в возрасте старше 6 лет и семейная агрегация (у отца диагностирована болезнь Бехтерева) [3].
При первом поступлении в НМИЦ здоровья детей у ребенка отмечалось развитие тяжелого полиартрита, ассоциированного с энтезитом. Неэффективность терапии НПВП и метотрексатом стала основанием для пересмотра проводимой терапии. Мальчику было показано назначение препарата из группы блокаторов TNF $\alpha$. Ребенок был включен в исследование эффективности и безопасности моноклональных антител к TNF $\alpha$ голимумаба. На фоне терапии голимумабом и метотрексатом у мальчика развилась лекарственная ремиссия заболевания. Через 1,5 года в связи с завершением исследования препарат был отменен. Учитывая отсутствие признаков активности болезни, ребенку была продолжена терапия метотрексатом в дозе 15 мг/м² поверхности тела в неделю. Через 4 мес у мальчика развился острый иридоциклит левого глаза, потребовавший проведения массивной противовоспалительной терапии с использованием ретробульбарных инъекций бетаметазона. Несмотря на проводимую терапию, воспалительные изменения в глазу сохранялись, развилось обострение суставного синдрома. Это послужило основанием для пересмотра проводимой терапии, и был сделан вывод, что при лечении увеитов, ассоциированных с ЮИА, наиболее изучен представитель моноклональных антител к TNF $\alpha$ адалимумаб. В исследовании S. Biester и соавт. у 17 из 18 пациентов с ЮИА, ассоциированным с увеитом, зафиксирован положительный эффект лечения адалимумабом ко 2-16-й нед; 16 пациентам удалось отменить преднизолон, у 1 - снизить его дозу. Эффективность лечения составила 88\% [15]. В исследовании K. Kotaniemi и соавт. адалимумаб получали 94 пациента с ЮИА, ассоциированным с увеитом. Из 54 пациентов, завершивших исследование, в 35\% случаев глюкокортикостероиды были отменены, а $31 \%$ пациентов значительно снижена их доза [16]. В своей работе Ruben Burgos-Vargas и соавт. изучили эффективность и безопасность адалимумаба в сравнении с плацебо у 46 детей с ювенильным артритом, ассоциированным с энтезитом. Средний возраст детей составил 12,9 \pm 2,9 года. В группе детей, получавших адалимумаб, эффект от терапии развивался чаще (62,6\%), в группе плацебо улучшения наблюдались лишь у 11,6\% ( $p=0,039)$. Длительность наблюдения составила до 52 нед. Частота побочных эффектов (боли в животе, головные боли, инфекционные осложнения) в группах адалимумаба и плацебо достоверно не различались (67,7 против 53,3; p>0,05) [13].

Таким образом, высокая эффективность адалимумаба у нашего пациента подтверждает данные других исследований.

\section{ЗАКЛЮЧЕНИЕ}

Представленный клинический случай показывает, что назначением человеческого моноклонального антитела к TNF $\alpha$ адалимумаба в сочетании с метотрексатом детям с быстро прогрессирующим артритом, ассоциированным с энтезитом и увеитом, неэффективностью монотерапии метотрексатом, весьма перспективно. Комбинация ингибитора TNF $\alpha$ с метотрексатом обеспечивает развитие ремиссии артрита и увеита, восстанов- 
ление функции в пораженных суставах, предотвращая инвалидизацию пациентов.

\section{ИСТОЧНИК ФИНАНСИРОВАНИЯ}

Не указан.

\section{КОНФЛИКТ ИНТЕРЕСОВ}

Е.И. Алексеева - получение исследовательских грантов от фармацевтических компаний Roche, Pfizer, Novartis.

\section{СПИСОК ЛИТЕРАТУРЫ}

1. Cassidy JT, Petty RE, Laxer RM, Lindsley CB. Textbook of pediatric rheumatology. 6th ed. Philadelphia: Saunders Company; 2001. pp. 218-322.

2. Petty RE, Southwood TR, Manners P, et al. International League of Associations for Rheumatology classification of juvenile idiopathic arthritis: second revision, Edmonton, 2001. J Rheumatol. 2004;31(2):390-392.

3. Детская ревматология. Атлас / Под ред. Баранова А.А., Алексеевой Е.И. 2-е издание, переработ. и доп. - М.: Педиатръ; 2015. - 384 c. [Detskaya revmatologiya. Atlas. Ed by Baranov A.A. Alexeeva E.I. 2nd ed, updated and revised. Moscow: Pediatr"”; 2015. 384 p. (In Russ).]

4. Алексеева Е.И., Литвицкий П.Ф. Ювенильный ревматоидный артрит: этиология, патогенез, клиника, алгоритмы диагностики и лечения. Руководство для врачей, преподавателей, научных сотрудников / Под общей ред. Баранова А.А. - М.: ВЕДИ; 2007. - 368 c. [Alexeeva El, Litvitskii PF. Yuvenil'nyi revmatoidnyi artrit: etiologiya, patogenez, klinika, algoritmy diagnostiki lecheniya. Rukovodstvo dlya vrachei, prepodavatelei, nauchnykh sotrudnikov. Ed by Baranov A.A. Moscow: VEDI; 2007. 368 p. (In Russ).]

5. Rosenberg KD, Feuer WJ, Davis JL. Ocular complications of pediatric uveitis. Ophthalmology. 2004;111(12):2299-2306. doi: 10.1016/j.ophtha.2004.06.014.

6. Hashkes PJ, Laxer RM. Medical treatment of juvenile idiopathic arthritis. JAMA. 2005;294(13):1671-1684. doi: 10.1001/jama. 294.13.1671.

7. Horneff G. Update on biologicals for treatment of juvenil eidiopathic arthritis. Exp Opin Biol Ther. 2013;13(3):361-376. doi: 10.1517/14712598.2013.735657.
Р. В. Денисова - получение исследовательских грантов от фармацевтических компаний Roche, Pfizer, Novartis.

А.М. Чомахидзе - отсутствие конфликта интересов, о котором необходимо сообщить.

\section{ORCID}

\section{Е.И. Алексеева}

http://orcid.org/0000-0002-3874-4721

Р. В. Денисова

http://orcid.org/0000-0002-1317-9914
8. Катаргина Л.А., Архипова Л.Т. Увеиты: патогенетическая иммуносупрессивная терапия. - Тверь; 2004. - 99 с. [Katargina LA, Arkhipova LT. Uveity: patogeneticheskaya immunosupressivnaya terapiya. Tver; 2004. 99 p. (In Russ).]

9. Катаргина Л.А., Хватова А.В. Эндогенные увеиты у детей и подростков. - М.: Медицина; 2000. - 320 с. [Katargina LA, Khvatova AV. Endogennye uveity u detei i podrostkov. Moscow: Meditsina; 2000. 320 p. (In Russ).]

10. Stoll ML, Cron RQ. Treatment of juvenile idiopathic arthritis: a revolution in care. Pediatr Rheumatol Online J. 2014;12:13. doi: 10.1186/1546-0096-12-13.

11. Lovell DJ, Ruperto N, Goodman S, et al. Adalimumab with or without methotrexate in juvenile rheumatoid arthritis. N Engl J Med. 2008;359(8):810-820. doi: 10.1056/NEJMoa0706290.

12. Lovell DJ, Ruperto N, Reiff A, et al. Long-term efficacy and safety of adalimumab for up to 6 years in patients with juvenile idiopathic arthritis. Arthritis Rheum. 2011;63(Suppl 10):265.

13. Burgos-Vargas R, Tse SML, Horneff G, et al. Efficacy and safety of adalimumab in pediatric patients with enthesitis related arthritis. Arthritis Rheumatol. 2014;66(S3):S4. doi: 10.1002/art.38414.

14. Imagawa T, Takei S, Umebayashi H, et al. Efficacy, pharmacokinetics, and safety of adalimumab in pediatric patients with juvenile idiopathic arthritis in Japan. Clin Rheumatol. 2012;31(12): 1713-1721. doi: 10.1007/s10067-012-2082-5.

15. Biester S, Deuter C, Michels $\mathrm{H}$, et al. Adalimumab in the therapy of uveitis in childhood. Br J Ophthalmol. 2007;91(3):319-324. doi: 10.1136/bjo.2006.103721.

16. Kotaniemi K, Saila H, Kautiainen H. Long-term efficacy of adalimumab in the treatment of uveitis associated with juvenile idiopathic arthritis. Clin Ophthalmol. 2011;5:1425-1429. doi: 10.2147/OPTH.S23646. 